\title{
College deviance and the effects on NFL amateur draft selection: Analyzing the Personal Conduct Policy
}

\author{
Michael Palmer ${ }^{\mathrm{a}}$, Quinlan Duhan ${ }^{\mathrm{b}}$ and Brian P. Soebbing ${ }^{\mathrm{c}, *}$ \\ ${ }^{a}$ University of Houston, Houston, TX, USA \\ ${ }^{\mathrm{b}}$ Louisiana State University, Baton Rouge, LA, USA \\ ${ }^{\mathrm{c}}$ Temple University, Philadelphia, PA, USA
}

\begin{abstract}
Over the past several decades, National Football League (NFL) executives have tried to devise ways to deter off-field misconduct of its players. Since the year 2000, the NFL instituted a Personal Conduct Policy governing the actions of players already in the league. The policy was further modified in April 2007 by Commissioner Roger Goodell. The question the present research asks is what is the relationship between an amateur player's misconduct in his final year of college and his overall pick in the NFL Draft. By extension, the present research looks to see if this relationship changes with the modification of the Personal Conduct Policy. Examining the NFL Draft from 1999 through 2013, the present research finds that misconduct decreased a player's draft position meaning his draft position improved. However, the modification of the Personal Conduct Policy leads to an insignificant result suggesting that team executives are beginning to examining an amateur player's misconduct more closely with the new policy.
\end{abstract}

Keywords: Misconduct, amateur draft, personal conduct, National Football League

\section{Introduction}

Research across many disciplines examined criminal and other defiant behaviors among athletes across various sport levels. Research examining professional sport and criminal/deviant behaviors focused on the policy implications for both the criminal justice system (McKelvey, 2001; O'Hear, 2001; Standen, 2009) and professional leagues and its member clubs (Ambrose, 2007; Kim \& Parlow, 2009; Ugolini, 2007). More recently, researchers begun to examine how off-thefield issues affect different stakeholders. Research by Weir and $\mathrm{Wu}$ (2014), for example, found that amateur

${ }^{*}$ Corresponding author: Brian P. Soebbing, Temple University, 1810 N. 13th Street, Speakman Hall 111 (006-68), Philadelphia, PA 19122, USA. Tel: +1 215204 8805; E-mail: brian.soebbing@temple.edu. players who were charged with a crime the year prior to being drafted were selected lower in the NFL Draft. If players were not charged with a crime but were accused of a crime, they were selected higher in the draft.

While recent research by Weir and Wu (2014) and others focused on the effect that negative off-field behavior affects a player's overall selection in the amateur draft, very little attention has been given to the role of league policy changes designed by league executives to deter negative off-field behavior. While most research focuses on the power of the commissioner and other league executives to change the policy, it is unclear the role that policy changes impacted player behavior or on additional consequences handed down by league or team executives on continued behavior that is deemed to be negative by the league and its member clubs. 
Thus, the purpose of the present research is to examine the impact that deviant behavior in an amateur football player's last season of college impacts his overall draft position in the National Football League Draft (NFL) and if this impact differs with a change in policy. The NFL Draft was instituted in 1936 and is the main mechanism used by the NFL to allocate amateur talent (Berri \& Simmons, 2011). Also, prior studies show that draft position is a significant indicator regarding playing time and career length (e.g., Hendricks, DeBrock, \& Koenker, 2003; Staw \& Hoang, 1995).

The sample time period examined in the present research is from the 1999 NFL Draft through the 2013 NFL Draft. This time period is significant for two reasons. First, player conduct was becoming an increasing point of emphasis for league executives. For example, a study of NFL players by Benedict and Yaeger (1998) in the 1996-1997 season found that 21 percent of players sampled were either arrested or indicted for a minimum of one crime in which the authors determined was a serious crime. The second reason is the presence of two commissioners in the NFL who had different policies governing off-field behavior during this time period. The first commissioner was Paul Tagliabue, who initially adopted the personal conduct policy in 2000. The second commissioner is Roger Goodell who modified the personal conduct policy in April 2007 to provide quicker and harsher punishments for off-field misconduct (Marks, 2008). Thus, the present study also examines the deviance and draft position relationship within the two commissioner regimes, something Weir and Wu's (2014) research could not accomplish.

Estimating a regression model with the dependent variable being the log of overall draft position, we find a player's deviance one year prior to the NFL Draft improves his overall draft position, meaning he is drafted higher in the NFL Draft under the original Personal Conduct Policy. However, examining the player's deviance one year prior to the draft under the Goodell era does not impact a player's draft position. Furthermore, the present research examines the relationship across different types of player subgroups-defensive skill players, offensive skill players, offensive linemen, and defensive lineman. The results show some variation regarding the impact of deviance on a player's overall amateur draft status under both Personal Conduct Policies.

The paper is structured as followed. The first section looks at the literature examining off-court issues in professional sports. The second section provides a brief history of the NFL's Personal Conduct Policy. The third section presents the data and estimation strategy for the present research. The fourth section presents the results followed by a discussion and conclusion section.

\section{Literature review}

Previous research examining off-field deviance issues in sports examined three specific streams. The first stream is a legal stream examining the role the commissioner and other league executives have in regards to their role in deterring unwanted offfield behavior (e.g., Ambrose, 2007; Bukowski, 2001; Jefferson, 1997; Kim \& Parlow, 2009; Mahone Jr., 2008; Marks, 2008; Stiglitz, 1994; Ugolini, 2007). Ambrose (2007) traced the development of off-field incidents and Personal Conduct Policies across the major North American sports leagues. Furthermore, he examined the role specific commissioners have played in various leagues with the development of conduct policies. Marks (2008) examined the legality of the Personal Conduct Policy as well as the impact of the policy that was developed outside of collective bargaining negotiations between the league and the NFL Players Association. Bukowski (2001) argued that the league and its executives were the best internal stakeholder group to punish players and other employees for off-field misconduct. Jefferson (1997) looked at the role the commissioner can play in punishing athletes who commit acts of domestic violence and the overall development of a policy against domestic violence. Mahone Jr (2008) specifically explored the role that Roger Goodell played in the modification of the NFL's Personal Conduct Policy.

The second stream examines the rule breakers themselves. Dabbs (1997) looked at the reasons provided as to why athletes are violent towards women. She outlined several theories used in the literature to explain a player's off-field behavior. Welch (1997) examined 100 NFL players who had committed various violent crimes against females. He found certain football positions, such as running backs, increased the chances that the player would commit some form of violent crime against a woman. O'Hear (2001) examined the sentencing of elite athletes who committed violent crimes. In his investigation, he found that sentencing laws differed between states as well as discussed the challenges of sentencing elite athletes compared to non-athletes. 
Anecdotally, Dohrmann (2011) conducted a study examining 2,827 players that were on rosters for Sports Illustrated's 2010 preseason top 25 college football ranking. Player's names, dates of birth and other vital information were run through databases and law-enforcement agencies. He indicated around seven percent of the players had been in trouble with the law either before or entering college, and nearly $40 \%$ of the incidents were considered serious offenses (Dohrmann, 2011). Weir and Wu (2014) stated the Seattle Seahawks did not draft a single player with a record of arrest or suspension between the 2005-2009 draft years, while the Cincinnati Bengals and Arizona Cardinals each had more than a quarter of their draft picks carrying some history of character concerns during that time period.

The third stream of research analyzes the impact that off-field behavior has on different stakeholder outcomes. Stair, Miza, Day, and Neral (2008) predicted that more arrests, on average, per team would negatively affect an NFL team's winning percentage. Poor team performance might be explained by players missing games due to suspensions from arrests or misconduct or the distraction of negative media attention resulting from arrests. Alternatively, arrests have been often linked with personality traits of aggression, a characteristic that may lead to increased performance on the field (Stair et al., 2008). Fink, Parker, Brett, and Higgins (2009) surveyed college students to look at the changes in fan identification after learning about off- field misconduct of athletes. Results from their survey indicated fan identification may be impacted, particularly if team executives do not manage their response to the off-field misconduct that is in accordance to fans expectations. Weir and Wu (2014) examined the relationship between criminal records and NFL draft position from 2005 to 2009. Examining criminal records and partitioning these records into arrested and charged and arrested and not charged, they found that when a player was arrested and charged with a crime, he was selected about a half of round later. However, their results found a player was drafted almost one full round earlier when he was arrested and not charged with a crime. Finally, Allen (2015) found the number of off-field incidents and suspensions did not impact a player's overall draft position.

Overall, scholars attempted to examine off-field criminal misconduct by professional athletes. This literature can be divided into three areas. Of particular interest in the present research is the final stream which focuses on the impact that off-field behavior has on different stakeholder outcomes. The outcome the present research looks to examine is a player's amateur draft position and the role that misconduct may influence in regards to the player's overall draft position. Previous research by Weir and $\mathrm{Wu}$ (2014) found evidence supporting the belief that off-field behavior influences overall draft position in the NFL. Due to the limited sample period, however, they did not look at the impact that changes to the league's Personal Conduct Policy has on this outcome. The present research seeks to examine this impact.

\section{NFL Personal Conduct Policy}

The commissioner of a professional sports league acts as the chief executive officer of the league (Noll, 2003). According to the NFL by-laws, ${ }^{1}$ the commissioner has many responsibilities. One of these responsibilities is to "adopt legal action or such other steps or procedures" when players, coaches, referees, or anybody else associated with the league is "guilty of any conduct detrimental either to the league, its member clubs or employees, or to professional football." As stated earlier, the NFL and its member clubs dealt with issues of player deviance off-the-field as well as on-field violence, where some has expressed concerns regarding the sport being too violent and aggressive. Ambrose (2007) stated that in the 1990 s, "'murder' was the only criminal offense said to bar an athlete from playing in the NFL." (p. 1071). Bukowski (2001) also stated that league executives were afraid that off-field misconduct was getting out of control that these actions would hurt the long-term survivability of the league. As a result, league executives attempted to improve the off-field conduct of its players when in contact with the general public.

Paul Tagliabue was the NFL commissioner from the 1989-1990 season until the 2005-2006 season. Given the reputation of the league and the perception of increased incidents, Tagliabue created a Personal Conduct Policy in 2000 (Marks, 2008). As the policy was written, many issues presented themselves which made it difficult for Tagliabue to attempt to deter player behavior. The policy was written so "punishments were not imposed until after a player had received either a conviction or its equivalent, such as a plea of no contest

\footnotetext{
${ }^{1}$ http://static.nfl.com/static/content//public/static/html/careers/ pdf/co_.pdf
} 
or a plea to a lesser charge. However, this policy precluded swift action and was thus apparently viewed as insufficient in quelling the rise in incidences of player misconduct and protecting the public image of the NFL" (Mahone Jr., 2008, p. 185-186). As Marks (2008) wrote, " $[\mathrm{t}] \mathrm{his}$ Personal Conduct Policy was not invoked often and had little effect on the negative publicity the NFL received for the indiscretions of its players" (p. 1581)

Since current commissioner Roger Goodell was appointed in 2006, he emphasized players conducting themselves properly off-the-field. Furthermore, Goodell modified the Personal Conduct Policy so that even athletes who were not convicted of a crime could still be punished by the league (Kim \& Parlow, 2009) since the conduct is determined to be detrimental to the league and might hurt public confidence in the legitimacy of the league's product (Ambrose, 2007). As Ambrose (2007) stated, three types of conduct can be disciplined by the league. These types are prohibited conduct, individuals charged with a criminal offense, and individuals convicted of crimes. After modifying the policy in April 2007, Goodell stated:

It is important that the NFL be represented consistently by outstanding people as well as great football players, coaches, and staff[...]. We hold ourselves to higher standards of responsible conduct because of what it means to be part of the National Football League. We have long had policies and programs designed to encourage responsible behavior, and this policy is a further step in ensuring that everyone who is part of the NFL meets that standard[... ] (USA Today, 2007, n.p.).

Given the attempt by league executives to deter improper off-field behavior that may impact the reputation and financial viability of the league, one may expect that team executives take an amateur player's off-field behavior into account when evaluating his potential selection in the NFL amateur draft. The impact that off-field misconduct has on an amateur player's draft position over these two policies is examined below.

\section{Data and empirical specifications}

To examine the impact that deviance in the year prior to the NFL draft affects an individual's draft position, the present research examines NFL picks from the 1999 NFL Draft through the 2013 NFL Draft. This sample period corresponds to the year prior to the implementation of the original Personal Conduct Policy through the change in NFL Commissioner. During the sample period, 4,061 selections were made by NFL teams. The dependent variable in the present research is the overall pick that the observed player was selected in the observed season (Overall Pick). This data was collected from Pro Football Reference. For each observation, data was collected on individual player characteristics including the drafted position of the player, the number of individual major college awards won during a player's college career, a player's age, the school the player attended prior to being selected in the NFL draft, and the player's participation in the NFL combine along with published performance results from the combine (e.g., 40-yard dash, height, weight, bench press repetitions).

To evaluate the overall pick $i$ in NFL Draft year $j$, the following empirical specification is estimated:

$$
\begin{aligned}
\beta_{i j}= & a_{i j}+\left\{3_{1} \text { OL }_{i j}+\left\{3_{2} \text { QB }_{i j}\right.\right. \\
& +\left\{3_{3} \text { DL }_{i j}+\left\{3_{4} \text { OffSkill }_{i j}\right.\right. \\
& +\left\{3_{5} \text { DefSkill }_{i j}+\left\{3_{6} \text { Awards }_{i j}\right.\right. \\
& +\left\{3_{7} \text { AllAmerican }_{i j}\right. \\
& +\left\{3_{8} \text { Age }_{i j}+\left\{3_{9} \text { Non D1FBS }_{i j}\right.\right. \\
& +\left\{3_{10} \text { NonBCSA }_{i j}\right. \\
& +\left\{3_{11} \text { CombinePart }_{i j}\right. \\
& +\left\{3_{12} \text { Deviance }_{i j}+\left\{3_{13} \text { Goodell }_{i j}\right.\right. \\
& +\left\{3_{14} \text { Deviance } * \text { Goodel }_{i j}+\varepsilon_{i j}\right.
\end{aligned}
$$

where $\sigma$ represents team fixed effects and $\varepsilon$ is the equation error term. The explanatory variables examine various factors that may affect the player's selection in the draft. The first six variables control for the various positions on the football field relative to the reference group (Special Teams). The positions were gathered from Pro Football Reference. The position groupings were partitioned in this way due to a wide discrepancy in the reporting of player positions during the time period. For example, between the period of 2005 and 2007, Pro Football Reference grouped the players into 13 specific classifications. However, in 2008 and subsequent years, a "reclassification" occurs opening up specialized positions. For example, 50 "defensive backs" were drafted in 2007. In 2008, the category of 
defensive backs was expanded and subsequently separated cornerbacks, strong safeties, and free safeties. In order to evaluate skill sets consistently, all positions were grouped into six pre-determined classifications. We identify six position groupings: quarterback, offensive skill (FB, RB, TE, and WR), offensive line, defensive line, defensive skill (DB and LB), and special teams. These six position variables are dummy variables equal to 1 if the player had that particular position listed as his draft position (e.g., QB), 0 otherwise.

The Awards variable looks at the cumulative number of individual major college awards ${ }^{2}$ (besides All American honors) won during a player's college career. AllAmerican is the cumulative the number of 1st, 2nd, or 3rd team All American awards won during the player's college career. The data for both of these variables were collected and verified from multiple websites. The Age variable is the age of the player at the time of the draft. As Rodenberg and Stone (2011) stated, the age variable is a proxy for competency, maturity, and ability. The Age variable was collected from Pro Football Reference.

Both NonDivlFBS and NonBCSAQ focus on the school the player attended the year before being selected. NonDivlFBS is a dummy variable equal to 1 if the observed player was drafted from a school that was not a Division I-FBS school while NonBC$S A Q$ is a dummy variable equal to 1 if the observed player did not play at a school that was part of a Bowl Championship Series automatic qualifying (BCSAQ) conference. It is expected both of these variables will have positive and significant coefficients as this result would be consistent with previous research incorporating these variables (e.g., Berri \& Simmons, 2011; Treme \& Allen, 2009) The variable CombinePart is a dummy variable equal to 1 if the player participated in one of the combine events besides being interviewed by teams. Data regarding combine participation was collected from the NFL Combine Results website.

The final three variables are the variables of interest in the present study. Deviance is the count of

\footnotetext{
${ }^{2}$ The individual awards (Position in parenthesis) were the John Mackey Award (TE), Lou Groza Award (K), Ray Guy Award (P), Rotary Lombardi Award (OL, DL, or LB), Outland Trophy (Interior Lineman), Bronco Nagurski Trophy (Top Defensive Player), Remington Trophy (Center), Heisman Trophy (Most Outstanding Player), Maxwell (College Player of the Year), Walter Camp Award (Outstanding player of the year), Doak Walker Award (RB), Davey O'Brien Award (QB), Fred Biletnikoff Award (WR), Dick Butkus Award (LB), Chuck Bednarik Award (Defensive Player of the Year), and Jim Thorpe Award (DB).
}

deviance issues a player accumulated 365 days prior to the NFL Draft. Deviance issues were analyzed on an individual basis for each player based on a predetermined set of search terms. For the purpose of the present study, deviance was classified with the following predetermined search terms: arrest, suspension, drugs, violence, off-field, misconduct, cheating, alcohol, scandal, fight, assault, and battery. These search terms revealed the newspaper articles containing one or more of the search terms as well as the player under examination. The newspaper articles were examined to make sure that the article was about the player committing one of these forms of deviance. Deviance issues were logged based on media exposure as disclosed by Factiva (academic license). The second variable is a dummy variable for the draft years after Roger Goodell took over as commissioner. Thus, the Goodell variable takes the value of 1 for the 2007 through 2013 drafts, 0 for all other draft years. The final variable is an interaction term between the previous two variables (Deviance ${ }^{*}$ Goodell). This variable examines the influence of deviance in years while Goodell is commissioner and its effect on a player's overall draft selection.

The present research also estimates a separate empirical specification looking specifically at players' NFL Combine performance. Equation 2 presents the model for the NFL combine participants.

$$
\begin{aligned}
\beta_{i j}= & a_{i j}+\left\{3_{1} \text { Award }_{i j}+\left\{3_{2} \text { AllAmerican }_{i j}\right.\right. \\
& +\left\{3_{3} \text { Age }_{i j}+\left\{3_{4} \text { NonD } 1 \text { FB }_{i j}\right.\right. \\
& +\left\{3_{5} \text { Non BCSA }_{i j}+\left\{3_{6} \text { Height }_{i j}\right.\right. \\
& +\left\{3_{7} \text { Weight }_{i j}+\left\{3_{8} 40 y d_{i j}\right.\right. \\
& +\left\{3_{9} \text { Bench }_{i j}+\left\{3_{10} \text { Vertical }_{i j}\right.\right. \\
& +\left\{3_{11} \text { Shuttle }_{i j}+\left\{3_{12} \text { Deviance }_{i j}\right.\right. \\
& +\left\{3_{13} \text { Goodell }_{i j}+\left\{3_{14}\right. \text { Deviance }\right. \\
& * \text { Goodell }_{i j}+\varepsilon_{i j}
\end{aligned}
$$

In Equation 2, all previous variables outlined above have the same descriptions. The new combine variables are taken from the NFL Combine Results Website. Previous research shown performance at the combine does influence overall draft position at certain positions (McGee \& Burkett, 2003). The first variable is the height of the player expressed in inches (Height). The second variable is the weight of the player expressed in pounds (Weight). 40yd is the player's forty yard dash time, Bench is the number of bench press repetitions a 
Table 1

Summary statistics

\begin{tabular}{|c|c|c|c|c|c|}
\hline Variable & Mean & Stnd Dev & Min & Max & $\mathrm{n}$ \\
\hline Overallpk & 4.551 & 0.960 & 0 & 5.568 & 4,061 \\
\hline $\mathrm{OL}$ & 0.165 & 0.371 & 0 & 1 & 4,061 \\
\hline QB & 0.048 & 0.214 & 0 & 1 & 4,061 \\
\hline $\mathrm{DL}$ & 0.175 & 0.380 & 0 & 1 & 4,061 \\
\hline Off Skill & 0.280 & 0.449 & 0 & 1 & 4,061 \\
\hline Def Skill & 0.315 & 0.464 & 0 & 1 & 4,061 \\
\hline SpecialTeams & 0.017 & 0.130 & 0 & 1 & 4,061 \\
\hline Awards & 0.053 & 0.333 & 0 & 6 & 4,061 \\
\hline All American & 0.171 & 0.446 & 0 & 3 & 4,061 \\
\hline Age & 22.654 & 0.892 & 20 & 29 & 4,061 \\
\hline NonD1FBS & 0.112 & 0.315 & 0 & 1 & 4,061 \\
\hline NonBCSAQ & 0.275 & 0.447 & 0 & 1 & 4,061 \\
\hline Combine Part & 0.711 & 0.453 & 0 & 1 & 4,061 \\
\hline Height (in) & 74 & 3 & 65 & 80 & 1,632 \\
\hline Weight (lbs) & 254 & 46 & 166 & 386 & 1,632 \\
\hline $40 y d$ & 4.80 & 0.32 & 4.21 & 5.68 & 1,632 \\
\hline Bench & 21.94 & 6.42 & 2.00 & 45.00 & 1,632 \\
\hline Vertical & 32.96 & 4.18 & 21.00 & 45.00 & 1,632 \\
\hline Shuttle & 4.39 & 0.27 & 3.75 & 5.26 & 1,632 \\
\hline Deviance & 0.117 & 0.872 & 0 & 19 & 4,061 \\
\hline Goodell & 0.438 & 0.496 & 0 & 1 & 4,061 \\
\hline Deviance*Goodell & 0.032 & 0.432 & 0 & 19 & 4,061 \\
\hline
\end{tabular}

player achieved at the combine, Vertical is the height of the player's vertical jump (expressed in inches), and Shuttle is the player's shuttle run time (expressed in seconds). Given the use of combine results in Equation 2, we expect the results to impact different positions in different ways (e.g., 40-yard dash time might mean more for the WR position than for the OL position). Instead of pooling all the positions together similar to Equation 1, we estimate Equation 2 separately for each position grouping identified in Equation 1 excluding special teams.

For both Equation 1 and Equation 2, there are several estimation issues that must be examined. The first is in regards to the dependent variable. Since the dependent variable is the order of selection in the draft, it could present some estimation issues in its current form. Thus, we take the logarithmic transformation of the Overall Pick variable to use in Equations 1 and 2. The second issue is in regards to heteroscedasticity of the equation error term. As a result, we use White's robust standard error correction in both equations consistent with previous research (Weir \& Wu, 2014). The third issue is multicollinearity. To address any potential issue with multicollinearity, variance inflation factors (vifs) are calculated. Results from these calculations for both equations do not indicate any potential issues with multicollinearity. The final issue has to do with the sample size for one of the position groupings in
Equation 2. The QB group did not contain enough observations to estimate a regression model. Thus, we only estimate regression models for the other four groups.

\section{Results}

Table 1 presents the summary statistics for the sample period. Recall there are 4,061 observations from 1999 through 2013. We find defensive skill players (DB and LB) make up the highest percentage of the observations at 31.5 percent of the overall sample. They are followed by offensive skill players (FB, RB, TE, and WR) at 28 percent and defensive lineman at 17.5 percent. The maximum number of major awards won was six (Manti Te'o, University of Notre Dame), and the maximum number of All-American honors was three (Barrett Jones, University of Alabama). The average age for a drafted player is 22 with 11 percent of the drafted players coming from non-Division 1-FBS programs and 27.5 percent coming from non BCSAQ schools. The majority of the observations (71 percent) participated in at least one event at the combine.

Finally, the maximum number of deviance hits from the Factiva database search for any one player was 19.

Table 2 presents the team fixed effects regression results for Equation 1. The model explained 22.7 
Table 2

Regression results

\begin{tabular}{lccr}
\hline Variable & Coef & Robust Stnd Error & $p$-value \\
\hline OL & -0.492 & 0.072 & $<0.001$ \\
QB & -0.840 & 0.120 & $<0.001$ \\
DL & -0.612 & 0.072 & $<0.001$ \\
OffSkill & -0.440 & 0.067 & $<.001$ \\
DefSkill & -0.465 & 0.066 & $<0.001$ \\
Awards & -0.478 & 0.087 & $<0.001$ \\
All American & -0.562 & 0.045 & $<0.001$ \\
Age & 0.164 & 0.016 & $<0.001$ \\
NonD1FBS & 0.195 & 0.039 & $<0.001$ \\
NonBCSAQ & 0.170 & 0.034 \\
Combine Part & -0.214 & 0.029 & $<0.001$ \\
Deviance & -0.044 & 0.023 & $<0.001$ \\
Goodell & 0.085 & 0.027 \\
Deviance*Goodell & 0.018 & 0.034 \\
Team Fixed Effects & & Yes \\
R2 & & 0.227 \\
Average VIF & & 2.680 \\
n & & 4,061 & 0.053 \\
\hline
\end{tabular}

percent of the observed variation for Overall Pick. We find most variables are significant at the 90 percent confidence interval or higher. All of the position variables are negative and significant compared to the reference group, which is special teams. The number of awards (both by position and All American), participating in the combine, and deviance variables are negative and significant. The Age, NonDIFBS, NonBCSAQ, and Goodell variables are positive and significant. Finally, the interaction term between deviance and Goodell is insignificant.

Table 3 presents the regression results for the four positional player groupings and the NFL combine data as described in Equation 2. All four models explain between 26.5 and 40 percent of the observed variation of the dependent variable. From Table 3, the number of non- All American awards is negative and significant for the defensive skill and defensive line players. The All American award is negative and significant for all positional groupings. The age variable is positive and significant for each grouping except for the offensive linemen.

Playing at a non-Division I-FBS school as well as a non-BCSAQ is insignificant for all groupings except for defensive skill positions. The height of the player at the NFL Combine is negative and significant for all groups except for defensive skill players. The weight of the player at the NFL Combine is negative and significant for three of the four positional groupings. The forty yard dash is positive and significant for all groupings while the bench press is significant for the offensive player groupings but not for the defensive player groupings. The vertical jump is significant for defensive skill and offensive linemen only and the shuttle run is insignificant in all the positional groupings. The deviance variable has a negative and significant influence for all the positional groupings except for defensive linemen while the interaction term (Deviance*Goodell) is only significant with the defensive skill position grouping.

\section{Discussion and conclusion}

Over the past decade, the NFL attempted to deter negative off-field behavior of its players by implementing and modifying a Personal Conduct Policy (Marks, 2008). With the adoption and modification of this policy, one might anticipate this policy would have an effect on where individual players are selected in the amateur draft. Previous research, examining over 1,200 amateur draft selection under the current personal conduct policy, found that certain incidences led to a player's overall amateur draft selection to be diminished (Weir \& Wu, 2014).

The present research attempts to examine both personal conduct policies looking at the 1999 through 2013 NFL Draft. Since the lower (higher) the number means the higher (lower) the draft position, the interpretation of a negative (positive) and significant coefficient means that the player's draft position improved (declined). There are two main variables of 


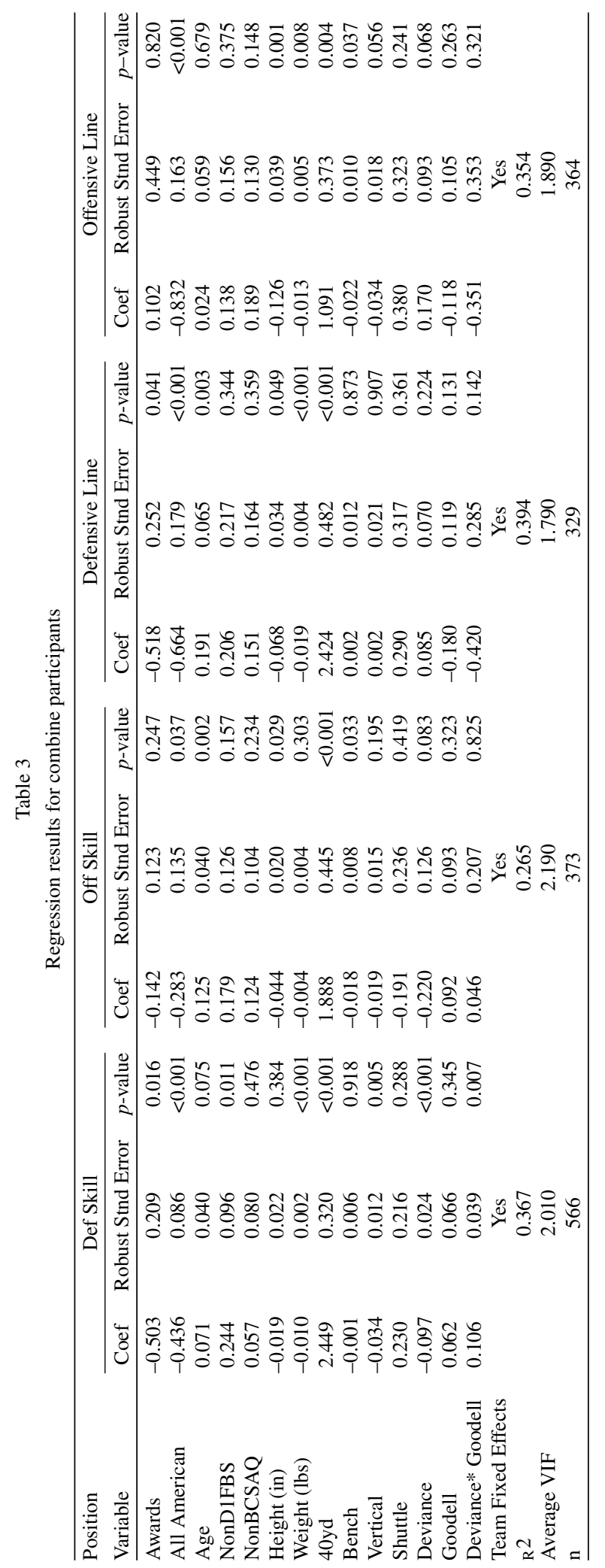


interest. The first variable of interest is the Deviance variable, which a count variable is looking at the number of newspaper articles in the 365 days prior to the draft that the player was mentioned under a set of general search criteria. Examining Table 2, we found an increase in the number of incidents mentioned lead to an improvement in draft position. Since the dependent variable is a natural log and the independent variable is not, we can provide a rough estimate of the impact of the independent variable on the dependent variable by multiplying the coefficient by 100 . Thus, the impact of an additional article in the newspaper regarding the misconduct of a player leads to an improvement in overall draft position of 4.4 percent.

There are many possible interpretations for why a positive and significant coefficient may occur. The first is the failure of the policy to actually change a team's drafting decision. If one of the purposes of the Personal Conduct Policy is to deter negative off-field behavior of players and, by extension, make teams aware of offfield issues more closely prior to acquiring a player, the results from Table 2 would suggest the initial policy did not influence a team's drafting decision. Furthermore, the original Personal Conduct Policy was written in such a manner that the commissioner could not punish the player until he was convicted or reached a plea deal (Mahone Jr., 2008). The lack of speed in punishing players and the overall ineffectiveness of the original policy would seem to have an effect on the negative and significant coefficient in Table 2. The second reason for the positive coefficient is it could be the Deviance variable is detecting aggressive behavior that is a desired quality for NFL teams according to previous research (e.g., Welch, 1997). The third reason is misconduct can be a form of risky behavior. As Bollinger and Hotchkiss (2003) stated in their analysis of MLB player salaries, workers whose performance is risky or more uncertain will earn a higher wage. Certainly any deviant behavior undertaken by individuals carries an element of risk both for the person as well as other stakeholder such as employers. However, team executives may want to take that risk of a player because of the potential for higher future rewards. The fourth reason is summarized by Bukowski (2001) when he stated " $[\mathrm{t}]$ eams wanted to win, so they overlooked all of the negative consequences that came with this talent. Talent wins games; it also buys second chances" (p. 109). In other words, teams are willing to overlook off-field behavior due to the talent possessed by these amateur players and the projection of how these amateur players will impact a team's future on-field performance.

The second variable of interest is the interaction between the number of mentions in the newspaper and the modified Personal Conduct Policy under Roger Goodell (Deviance*Goodell). Examining Table 2, we find this variable to be insignificant. Taken this variable along with the Deviance variable, we can say that under the previous Personal Conduct Policy, players were rewarded in terms of a better draft position with an increase in deviance. However, this advantage has since gone away with the introduction of the modified Personal Conduct Policy under Goodell, which provides quicker and harsher penalties for players whose off-field behavior does not coincide with the values of the league.

Table 3 specifically examines NFL Combine participants across four different player groups. From Table 3, notice the deviance variable is negative and significant for both the offensive and defensive skill position players at the 90 and 99 percent confidence interval respectively. However, the number of mentions in the newspaper did not affect the draft position of offensive and defensive lineman. Examining the interaction variable, this variable is insignificant for all positions except for defensive skill position players. For the defensive skill position players, there is a positive and significant increase in draft position meaning each additional mention in the newspaper leads to a lower draft position. One possible explanation revolves around risky workers (Bollinger \& Hotchkiss, 2003) as this position grouping may not be the area in which team executives want players taking risks on the field due to potentially giving up 7 points. Thus, this risky action of off-field misconduct may signal behaviors teams do not want to see with defensive skill position players.

Other variables within the model also provide interesting results. In Table 2, all of the five position groups have a higher draft position in comparison to the reference group (Special Teams). These results are not surprising given that special teams players, in particular kickers and punters, are generally selected towards the end of the NFL draft. The number of awards the player won during his college career as well as the number of All American honors leads to an improved draft position. These results would intuitively make sense given that these awards are given to the top player of his respective position or position group (e.g., Defense). Examining the results in Table 3, awards and All Amer- 
ican honors affect different position groups differently. The results in Table 3 show an increase in the Awards variable leads to a defensive player being selected lower in the draft. For offensive players, awards do not influence draft position. There may be a couple of explanations for this result. The first explanation could be the skill set needed to succeed in the NFL is more transferable of the player receiving the awards on defense compared to players who receive the awards on offense. The second explanation could be that the awards is indicative of a high quality player on defense and is used by NFL team scouting departments to help decipher quality compared to offense awards. Examining the results for the All American variable in both Tables 2 and 3, it is negative and statistically significant across all models indicating the more All American awards the player receives leads to an improved overall draft position. We also find the older the player is, his overall selection is diminished. This positive and significant effect occurs in four of the five models in Tables 2 and 3 with the offensive linemen model in Table 3 being the only insignificant result.

Examining the university characteristics, the results in Table 2 indicate playing at a non-Division 1-FBS school and at non-BCSAQ increase the player's overall selection, meaning a player is selected in later rounds of the draft. This result intuitively makes sense and is consistent with previous research (e.g., Treme \& Allen, 2009) as players who play at the top schools generally face stronger competition over the course of their careers allowing NFL scouts to have a better idea of how the player may project as an NFL player. Examining these two variables in Table 3, we find insignificant results in all four models except for the defensive skill position. For this variable, we find that playing at a nonDivision I-FBS school led to a selection in the higher rounds of the NFL draft.

The final group of variables specifically examines a player's participation in the combine and some of the player's performance results from the combine. Regarding Table 2, there is a dummy variable for if the observed player participated in at least one event of the NFL Combine. The results from this variable in Table 2 shows that participating in the NFL Combine led to a significant decrease in overall draft selection, meaning that the player was draft lower in the draft. While this result is not surprising given the NFL would invite some of the top draftees to the combine, players have the ability to voluntarily not participate in the combine due to personal choice or injury. Thus, participating in the combine does provide benefit to those players. Table 3 presents the results that include six combine specific variables, the listed height and weight of the player and the performance of the player in the 40-yard dash, bench press, vertical jump, and shuttle run. In regards to the height variable, we find that height is a significant predictor of draft selection for offensive skill players, defensive lineman and offensive lineman. More precisely, height improves the overall draft positions for players of these three positions. These results support previous research examining height and draft selection in the National Basketball Association (NBA) (Berri, Brook, \& Fenn, 2011). Across all four position groups, an increase in the player's weight improves his overall selection in the draft.

Examining the combine performance variables, the results from Table 3 show an increase in the 40 yard dash time leads to an increase in a player's overall draft selection. In other words, the slower a player is at the combine, he is selected in the higher rounds of the amateur draft.

We find that an increase in the amount of repetitions on the bench press increase lowers the player's overall selection in the draft for offensive players. For defensive players, the number of repetitions on the bench press does not impact draft position. The results from the vertical jump shows different results for defensive skill players and offensive linemen compared to offensive skill and defensive linemen. For the defensive skill players and offensive lineman, the higher the vertical jump leads to a lower overall selection in the amateur draft. For the other two player groupings, the performance in the vertical jump does not impact overall draft selection. Finally, the shuttle run does not impact overall draft position for all four player groupings.

In summary, the results showed that an increase in the number of deviance incidents in the year prior to being selected in the NFL Amateur draft improves a player's overall draft spot. When partitioning the sample into four player groupings, we find this relationship to be consistent with both defensive and offensive skill players. However, the opposite relationship for offensive lineman occurs in regards to deviance. Of particular interest in the present research is to see how the relationship between deviance and draft status changes with the modification of the Personal Conduct Policy under Roger Goodell. We find that deviance under Goodell is generally insignificant in regards to a player's overall draft status except for Defensive Skill players who sees their overall draft selection diminish. 
From the present research, we can say that the modification of the Personal Conduct Policy did begin to change the behavior of teams in evaluating amateur players.

The presentation is not without its limitations. The biggest limitation of the present research is that deviance itself is hard to quantify. As Weir and $\mathrm{Wu}$ (2014) stated, it is difficult to arrive at an accurate estimate of a player's off-field misbehavior. The measure used here in the present study is comprised of only incidents and the media attention related to those incidents. Thus, there may be incidents that do not receive any attention that would fall into the search terms outlined above. Furthermore, the measure does not separate types of incidents. From the search terms used to generate the newspaper counts, there are many possible behaviors that players could have undertaken as well as many different types of punishments both from a team standpoint (e.g., suspension) and a legal standpoint (e.g., jail, plea agreement) that are not quantified within this analysis. The nature and types of negative off-field behavior might take more precedent for team executives and evaluators.

Another limitation is we only examine the players that were selected in the NFL Draft. Pager (2003) noted a player's criminal record can close doors in many employment situations because the establishment may not always probe deeper in the context or possible complexities of a situation. Thus, there could be players with on-field talent to be drafted, however, character and/or legal issues may have prevented NFL teams from drafting the players. The present research cannot account for that scenario. Thus future research should further examine these incidents to look at the impact the Personal Conduct Policy has on an amateur player's draft status.

\section{References}

Allen, W.D., 2015. The demand for younger and older workers: Patterns from NFL labor markets. Journal of Sports Economics. 16, 127-158.

Ambrose, R., 2007. The NFL makes it rain: Through strict enforcement of its conduct policy, the NFL protects its integrity, wealth, and popularity. William Mitchell Law Review Journal. 34, 1069-1113.

Benedict, J., Yaeger, D., 1998. Pros and cons: The criminals who play in the NFL. New York, NY: Warner Books Inc.

Berri, D.J., Brook, S.L., Fenn, A.J., 2011. From college to the pros: Predicting the NBA amateur player draft. Journal of Productivity Analysis. 35, 25-35.
Berri, D.J., Simmons, R., 2011. Catching a draft: On the process of selecting quarterbacks in the National Football League amateur draft. Journal of Productivity Analysis. 35, 37-49.

Bollinger, C.R., Hotchkiss, J.L., 2003. The upside potential of hiring risky workers: Evidence from the baseball industry. Journal of Labor Economics. 21, 923-944.

Bukowski, S., 2001. Flag on the play: 25 to life for the offense of murder. Vanderbilt Journal of Entertainment Law \& Practice. 3, 106-123.

Dabbs, E.E., 1997. Intentional fouls: Athletes and violence against women. Columbia Journal of Law \& Social Problems. 31, 167-199.

Dohrmann, G., 2011. Rap sheets, recruits, and repercussions. Sports Illustrated. Retrieved from http://www.si.com/ vault/2011/03/07/106043456/rap-sheets-recruits-and-repercu ssions

Fink, J.S., Parker, H.M., Brett, M., Higgins, J., 2009. Off-field behavior of athletes and team identification: Using Social Identity Theory and Balance Theory to explain fan reactions. Journal of Sport Management. 23, 142-155.

Hendricks, W., DeBrock, L., Koenker, R., 2003. Uncertainty, hiring, and subsequent performance: The NFL Draft. Journal of Labor Economics. 21, 857-886.

Jefferson, A.L., 1997. The NFL and domestic violence: The commissioner's power to punish domestic abusers. Seton Hall Journal of Sport Law. 7, 353-390.

Kim, J.Y., Parlow, M.J., 2009. Off-court misbehavior: Sports leagues and private punishment. Journal of Criminal Law \& Criminology. 99, 573-597.

Mahone, Jr., M.A., 2008. Note: Sentencing guidelines for the court of public opinion: An analysis of the National Football League's revised personal conduct policy. Vanderbilt Journal of Entertainment and Technology Law. 11, 181-210.

Marks, A.B., 2008. Personnel foul on the National Football League Players Association: How union executive director Gene Upshaw failed the union's members by not fighting the enactment of the personal conduct policy. Connecticut Law Review. 40, 1581-1622.

McGee, K.J., Burkett, L.N., 2003. The National Football League combine: A reliable predictor of draft status? Journal of Strength and Conditioning Research. 17, 6-11.

McKelvey, M., 2001. Separating sports and real life: How professional sports leagues' collective bargaining agreements keep athletes out of the criminal justice system. New Eng J on Crim \& Civ Confinement. 27, 91-130.

Noll, R.G., 2003. The organization of sports leagues. Oxford Review of Economic Policy. 19, 530-551.

O'Hear, M.M., 2001. Blue-collar crimes/white-collar criminals: Sentencing elite athletes who commit violent crimes. Mississippi State Law Review. 12, 427-447.

Pager, D., 2003. The mark of a criminal record. American Journal of Sociology. 108, 937-975.

Rodenberg, R.M., Stone, D.F., 2011. The short and long-run labor market effects of age eligibility rules: Evidence from women's professional tennis. Journal of Labor Research. 32, 181-198. 
Stair, A., Mizak, D., Day, A., Neral, J., 2008. The factors affecting team performance in the NFL: Does off-field conduct matter? Economics Bulletin. 26(2), 1-9.

Standen, J., 2009. The manly sports: The problematic use of criminal law to regulate sports violence. Journal of Criminal Law \& Criminology. 99, 619-642.

Staw, B.M., Hoang, H., 1995. Sunk costs in the NBA: Why draft order affects playing time and survival in professional basketball. Administrative Science Quarterly. 40, 474-494.

Stiglitz, J., 1994. Player discipline in team sports. Marquette Sports Law Journal. 5, 167-188.

Treme, J., \& Allen, S. K. (2009). Widely received: Payoffs to player attributes in the NFL. Economics Bulletin. 29, 1631-1643.
Ugolini, J.M., 2007. Even a violent game has its limits: A look at the NFL's responsibility for the behavior of its players. University of Toledo Law Review. 39, 41-58.

USA Today 2007. Goodell strengthens NFL personal conduct policy. Retrieved from http://www.usatoday.com/ sports/football/nfl/2007-04-10-new-conduct-policy_N.htm? $\operatorname{csp}=34$ (n.p.).

Weir, K., Wu, S., 2014. Criminal records and the labor market for professional athletes: The case of the national football league. Journal of Sports Economics. 15, 617-635.

Welch, M., 1997. Violence against women by professional football players: A gender analysis of hypermasculinity, positional status, narcissism, and entitlement. Journal of Sport \& Social Issues. 21, 392-411. 